\title{
MYSTERY OF THE NECK SINUS
}

\author{
Ranawaka U A R S ${ }^{1}$, Lamahewage A K ${ }^{2}$ \\ ${ }^{1}$ Senior Registrar in Paediatric Surgery, Lady Ridgeway Hospital for Children, Sri Lanka. \\ ${ }^{2}$ Consultant Paediatric Surgeon, Lady Ridgeway Hospital for Children, Sri Lanka.
}

UAR S Ranawaka MBBS, MS, MRCS Senior Registrar in Paediatric Surgery, Lady Ridgeway Hospital for Children, Sri Lanka.

A KLamahewage MBBS, MS, FRCS

Consultant Paediatric Surgeon,

Lady Ridgeway Hospital for Children, Sri Lanka.

\section{Introduction}

A five-year old boy with about one month's history of discharging skin sinus over left side of the neck was referred to the surgical clinic due to failure of resolving the lesion with oral antibiotics.

He has been otherwise well with no known comorbidities. There was no contact history of tuberculosis and he had no previous similar discharging lesions.

The ESR was repeatedly normal. The full blood count, X-ray neck and chest X-ray were normal.
Initial wound scooping was performed with a plan to perform formal sinus tract excision once infection settled.

At the second surgery for excision of the sinus tract, underlying the unhealthy granulation tissue a tip of a plastic pen knob was found closer to the carotid sheath.

Removal of the foreign body and the granulomatous tissue was performed. On questioning back post operatively, his grandmother had recalled that 3 years ago, the child had been playing with a pen and the plastic tip was found missing. Subsequently he had complained of left sided neck pain for a few days. The pain had settled down on its own. Thereafter the incident had been forgotten. On subsequent clinic follow up, the child was symptom free.

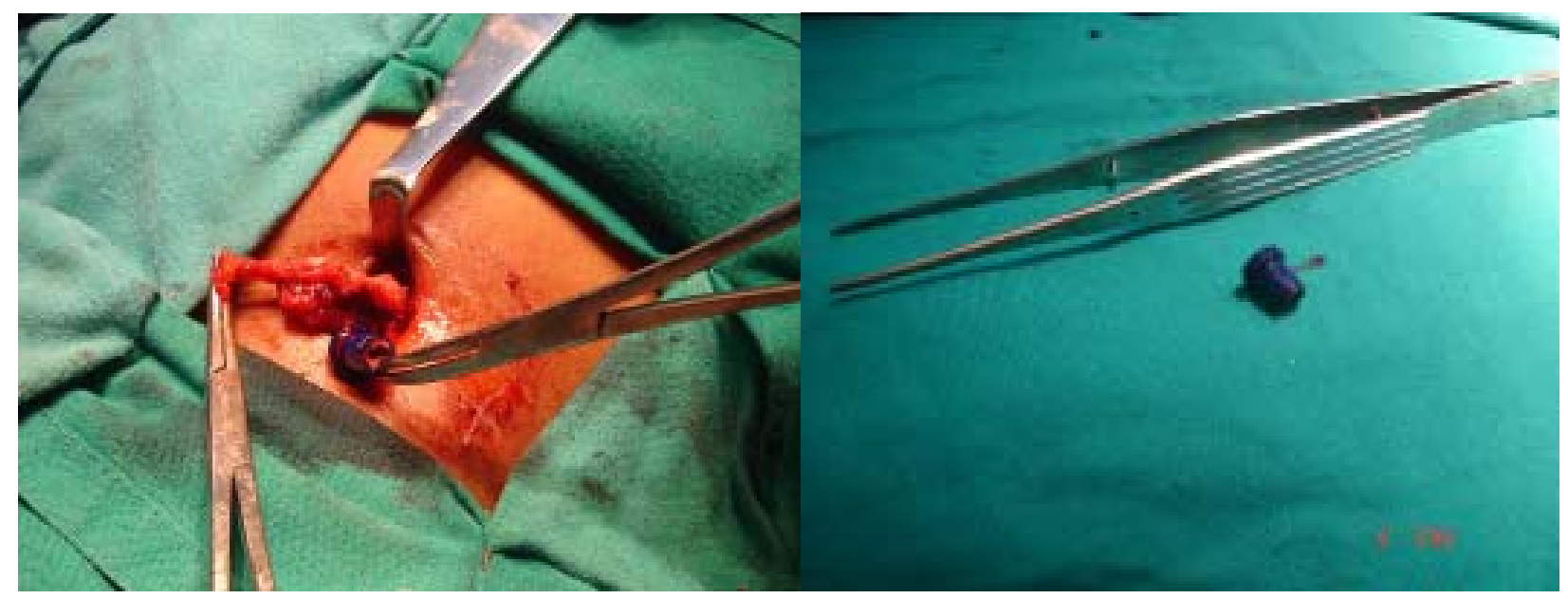

Figure 1. Excision of the sinus tract.

Figure 2. Foreign body-plastic pen knob. 


\section{Discussion}

The accidentally swallowed foreign body of about $1 \times 0.5 \mathrm{~cm}$ size is comparatively large for the then 2-year old baby's oesophagus. It had migrated through the wall of the oesophagus and had induced a granulomatous inflammation resulting in the neck sinus.

This type of occurrences is rare in the literature $(1,2,3,4,5)$. Therefore, a foreign body as the aetiology was neither suspected at the onset of the symptoms nor at the second surgery for excision of the sinus tract.

The experience of suddenly visualising a plastic object on exploration of a chronically discharging neck sinus is indeed a rare experience in life worth sharing.

\section{References}

1. Farmakakis T, Dessypris N, Alexe DM, et al. Magnitude and object-specific hazards of aspiration and ingestion injuries among children in Greece. Int $J$ Pediatr Otorhinolaryngol 2007; 71(2): 317-24. Epub 2006 Nov 28.

2. Chung SM, Kim HS, Park EH. Migrating pharyngeal foreign bodies: a series of four cases of saw-toothed fish bones. Eur Arch Otorhinolaryngol 2008; 265(9): 1125-9. Epub 2008 Jan 4.

3. Maseda E, Ablanedo A, Baldó C, Fernández MJ. Migration and extrusion from the upper digestive tract to the skin of the neck of a foreign body (fish bone). Acta Otorrinolaringol Esp 2006; 57(10): 474-6.

4. Joshi AA, Bradoo RA. A foreign body in the pharynx migrating through the internal jugular vein. Department of ENT, Lokmanya Tilak Municipal Medical College and General Hospital, 1/15 Sardar Nagar No. 4, Antop Hill, Sion (E), Mumbai 400 037, India.

5. Osinubi OA, Osiname AI, Pal A, Lonsdale RJ, Butcher C. Foreign body in the throat migrating through the common carotid artery. Department of Otolaryngology, King's Mill Hospital, Suttonin-Ashfield, Nottinghamshire, UK. 